FROM THE MSSVD

\title{
The MSSVD, the National Sexual Health and HIV strategy for England and genitourinary medicine education
}

A fundamental remit of the MSSVD has always been sexual health education and training, especially for those within the specialty. With the possibility of, and subsequent publication of, the National Sexual Health and HIV strategy (SHS) for England ${ }^{1}$ the MSSVD has broadened its influence in the area of sexual health education. As a multiprofessional society the MSSVD is ideally placed to respond to the needs of those multiprofessional and multidisciplinary groups who it is proposed will deliver the SHS.

The MSSVD produced an in-depth response to the SHS, ${ }^{2}$ which included an appendix on the training and educational needs of those working at all levels: from undergraduates through to the specialist level 3.

For the SHS to be successfully implemented appropriate skill, attitude, and knowledge based education and training of healthcare workers expected to deliver levels 1, 2, and 3 services is essential. Many level 1 providers have only received genitourinary medicine training through undergraduate programmes. These are documented as being very patchy for both doctors and nurses. Even for those currently working within genitourinary medicine there is variable access to training (unpublished survey by GUM non-consultant career grade group, 2002)

\section{Undergraduates}

An MSSVD working party has been established with input from the British HIV Association (BHIVA) and the Faculty of Family Planning and Reproductive Health Care (FFPRHC). The aim is to define a core minimum sexual health curriculum for all universities, both nursing and medical and to develop and pilot a modular training programme, which can be adapted locally.

\section{Level 1}

In anticipation of the increased involvement of primary care in the delivery of sexual health care following the publication of the sexual health strategy, the MSSVD identified the need for basic training. A working group was established in mid-2000 and developed the sexually transmitted infection foundation course, STIF. This is a 2 day multidisciplinary course for healthcare workers from primary care, family planning, school nurses, secondary care clinicians who may encounter patients with sexually transmitted infections
(STIs) (for example, obstetrics and gynaecology, rheumatology, ophthalmology, accident and emergency), newcomers to GUM, etc. The course aims to equip participants with the basic knowledge, skills, and attitudes for the effective management of STIs. It was piloted in 2001 and fully launched in January 2002. Since then there have been 31 courses with more than 1100 delegates. In June 2002 an open meeting was held of all course directors and the material has been revised in light of the evaluations and feedback. The overall evaluation of the course has been excellent and is available on the MSSVD website, STIF subsection. The steering group is currently exploring the possibility of external quality assurance.

The steering group includes representation from the Royal College of General Practitioners, the Royal College of Nursing, and the Faculty of Family Planning. The DFFP has recently been modified to include two modules in STIs but those who have attended an STIF course will be exempt from these modules. Already there are many examples of collaborative working with family planning running STIF courses and DFFP courses to complement one another.

A major limiting factor for attendance at the course is the cost of GP locum provision. It is recognised that the course is a foundation course and additional opportunities need to be developed locally especially for development of practical skills.

Level 2: general practitioners with a special clinical interest in sexual health An MSSVD working group has met to look at the issues for level 2 practitioners as defined by the SHS, including developing a curriculum and means of assessment and evaluation. There are ongoing discussions with the Royal College of General Practitioners about level 2 practitioners, which include the role and remit of general practitioners with a special clinical interest in sexual health (included in the current roll out of the Department of Health programme). Genitourinary medicine clinicians need to be integrally involved in training, assessment, and ongoing clinical professional development (CPD) of these practitioners

\section{Level 3: specialist services}

The MSSVD has always had a major role in providing education events for the specialty through the ordinary general meetings, HIV masterclass, the annual spring meeting, and joint meetings with other colleges and faculties including Royal College of Physicians (RCP), Royal College of Obstetrics and Gynaecology, FFPRHC, RSM sections and forums. In recent years innovative approaches have been taken with the format of some of these meetings using more interactive techniques. These have increasingly had a multiprofessional approach and in the next academic year the focus of one meeting will be on primary care liaison.

In 1999 the MSSVD assumed responsibility for the 10 day modular course in STIs and HIV, which had previously been run by the British Postgraduate Medical Federation and subsequently London University. The course is held twice yearly in central London. Since the MSSVD assumed responsibility, registration fees have fallen and attendance has nearly doubled, such that all courses are fully subscribed. The educational level of the course is now tailored to that of specialist registrars (SpRs) at the end of their first year in genitourinary medicine and most SpRs in the United Kingdom now attend early in their training. The content of the course closely matches the curriculum for the Diploma in Genitourinary Medicine of the Society of Apothecaries, London. Acquisition of the diploma will become compulsory for all SpRs enrolling for training from January 2003 as part of their assessment. In the past 2 years the course has been opened to non-medical delegates; nurses, health advisers, and scientists working in the fields of GUM and HIV have attended

Accreditation of the course is being sought from a university to enable it to count towards a higher degree for specialist nurses in GUM. This has been part of the thrust of another MSSVD working group looking at the role of the advanced nurse in GUM and developing a framework for nurses wishing to work at an advanced level. This group is now combining forces with the Royal College of Nursing, which has the remit of producing a CD Rom for sexual health education for nurses.

In December 2002 a pilot for a diploma in HIV medicine was held, aimed at SpRs towards the end of their training. The MSSVD and BHIVA have established a joint working group to assess the educational needs of those sitting the examination and various options for providing appropriate training are being explored.

Within the specialty there are a large number of non-consultant career grade 
doctors (NCCGs) on whom many of us rely to deliver the clinical service. A recent workforce survey has found that $32 \%$ of clinical assistants work only in GUM and therefore have no links to any college for CPD. The RCP is aware of the needs of these doctors and offers associate membership of the RCP to oversee their CPD.

More recently a survey among the delegates attending the 2002 NCCG annual conference found that the majority had not been granted study leave funding to attend the meeting and were self funding. The same survey found that of the NCCG doctors working in GUM alone a large proportion have no entitlement to study leave, either time or financial support, through their local employer. This has since been raised with the RCP and is being addressed through their NCCG and CPD committees.

\section{The future}

Distance learning tools are being investigated as well as web based tools for existing courses to enhance the material provided.

The MSSVD has run a TIPS teaching course. All consultants have a professional as well as clinical CPD requirement and it might be that those interested in teaching who have not yet done so would be advised to attend a teaching/ training course.

HIV and sexually transmitted infections are global issues. MSSVD as a specialist society has the largest membership of healthcare workers involved in sexually transmitted infection and HIV service and training. It is well placed to work in partnership with other organisations to support more education globally with appropriate funding.

In summary, the education and training of all involved healthcare workers is essential to underpin the successful implementation of the National Sexual Health and HIV strategy. The time and finance need to be in place at all levels to allow professionals to be trained and trainers to train. The MSSVD has been proactive and imaginative in its approach to education. All members have a critical role in developing, delivering and supporting training across the levels to provide good quality sexual health services wherever they are delivered.

J Sherrard

MSSVD education subcommittee member, Department of Genitourinary Medicine, Radcliffe Infirmary, Woodstock Road, Oxford OX2 6HE, UK

A J Robinson

President MSSVD, Department of Genitourinary Medicine, Mortimer Market Centre, Off Capper Street, London WCIE 6AU, UK

Correspondence to: Jackie Sherrard; jackiesherrard@doctors.org.uk

\section{References}

1 Department of Health. The national sexual health and HIV. London: DoH, 2001

2 MSSVD. Response to the National Sexual

Health and HIV (www.mssvd.org.uk).

3 Cowan FM, Dhar J, Ainsworth J, et al. Undergraduate teaching of genitourinary medicine in Britain - what are the issues? Genitourin Med 1996:72:6-8.

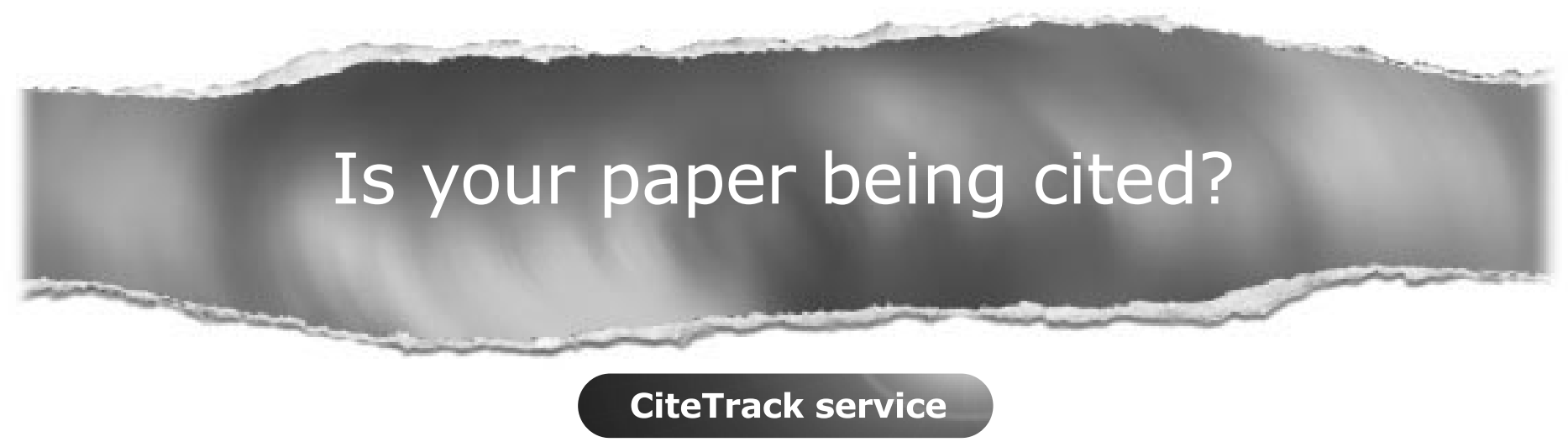

CiteTrack will alert you by email whenever new content in Sexually Transmitted Infections or a participating journal is published that matches criteria you want to track

Topics: Tell CiteTrack which words or subjects to watch for in new content Authors: Be alerted whenever key authors you are following publish a new paper Articles: Know whenever a paper of interest to you is referenced by another paper

\section{www.stijournal.com}

